\title{
Load Distribution Factor before and after Widening of Existing T-beam Bridges
}

\author{
L.P.Huang ${ }^{1}$, S.G.Cao ${ }^{2}$, C.L.Wei ${ }^{1}$, Z.G.Chang ${ }^{3}$, X.C.Zhang ${ }^{4}$ and Y.Z.Huang $^{1}$ \\ ${ }^{1}$ School of Civil Engineering of Changsha University, Changsha, Hunan 410003, China \\ ${ }^{2} Z$ Zhejiang Scientific Research Institute of Transport, Hangzhou, Zhejiang 311305, China \\ ${ }^{3}$ Changsha Planning \& Design Institute CO., LTD, Changsha, Hunan 410007, China \\ ${ }^{4}$ School of Chemistry, Physics, Mechanical Engineering, Science, and Engineering Faculty, Queensland University of Technology, \\ Brisbane, QLD 4001, Australia
}

Received 19 February 2017; Accepted 27 June 2017

\begin{abstract}
Load distribution factor (LDF) is an important index for evaluating the performance of existing bridges. However, few researchers have studied the change of transverse load distribution coefficients of beams before and after the widening and reinforcement of existing bridges. To work out such problem, a reinforcement method for widening longitudinal and cross beam was proposed. A Finite element (FE) model was built to simulate the widening reinforcement of existing bridge, Load distribution factor for all girders were analyzed in the cases of different position, quantity and stiffness of cross beam, different added width of girder, different existing bridge stiffness and different connection system. Results show that the LDF of side beams decreases by $63.92 \%$ to the highest extent after bridge reinforcement, which significantly improves load-carrying condition of girder. However, the LDF at fulcrum increases by $30 \%$ after reinforcement. Therefore, some strengthening measures are necessary in these positions. The quantity, position and dimension of cross beam have not much influence on the LDF of each girder. The LDF of beams are smaller when the widened girders are connected rigidly to the old girders than that hinge connected to. The LDF of each girder shows not much difference when the main beams are connected to widened girders with rigid or hinged connection, respectively. This study is meaningful for the development of widening and reinforcement design of existing bridges.
\end{abstract}

Keywords: Load distribution factor, Old bridge widening, Method of rigid-joint girder, Transverse beam

\section{Introduction}

Most of existing bridges in China were established from the 1950 s to 1980 s. The rapid increase in traffic and overloaded vehicles has brought considerable damage to highway bridges [1]. The problems such as concrete cracks and flaking occurred on the hinge joint of bridge decks. More seriously, the holes may come out in the concrete around the hinge joint and then no connection exists in the transverse direction, which makes single beam carry the entire vehicle load in transverse direction [2].

At present, with the rapid development of economy, the repair and reinforcement of old bridges have gradually become a hot industry [3]. It does not only waste construction resources but also causes long-term traffic interruption and negative social influence for dismantling old bridges, which have low bearing capacity and narrow decks. Moreover, the wasted concrete from old bridges will cause environmental pollution. By contrast, the widening and reinforcement of existing bridges during highway reconstruction will bring numerous benefits, such as resource saving, shorter time for traffic interruption.

Load distribution factor (LDF) is an important index for bridge assessment [4]. As a practical approximate index of

\footnotetext{
*E-mail address: huanglipu@163.com

ISSN: $1791-2377$ @ 2017 Eastern Macedonia and Thrace Institute of Technology. All rights reserved. doi:10.25103/jestr.103.13
}

spatial internal force, the LDF of highway bridges is a crucial part of bridge design. In particular, many bridges need to be reinforced and reconstructed. This process will change a bridge's system and stress distribution, thus changing the LDF of beams relatively [5]. However, these methods focus on existing bridges or new bridges only but not for the widening and reinforcement of old bridges, as well as corresponding variations of the LDF of beams.

The variation law of the LDF of beams during reconstruction of old bridges needs urgent exploration. In this study, the LDF after widening and reinforcement were compared with previous ones. Changes in the LDF during widening and reinforcement were discussed.

\section{State of the art}

Although studies on the reconstruction of existing bridges have referred the significance of widening and reinforcement, respectively, few of them have referred two contents together. The widening of existing bridges was studied early from 1976 to 1980 by the National Highway Survey and Design Institute and the National Road Scientific Research Institute of Ukraine. They developed several bridge widening techniques and applied them successfully in practical engineering projects. Germany has studied highway widening since 1987. The German Highway Department published the atlas of preliminary technical design for bridge widening. The design and technical state of 
structures of a sort was considered in the atlas [6], but the bridge performance after reinforcement was not referred. Previous studies on bridge superstructure widening can be summarized into the following three modes: adding beams on one side, symmetric use of beams for widening of Tshaped bridge (joints), and replacing the original T-shaped beam with frame reinforcement prestressed girder [7]. None of them contained the changes of LDF during the process of reinforcement. Chai and Hung [8] studied the timedependent characteristics of differential settlement between the new beams and the winded beams, but they did not explore the influences of rigidity changes on the widened bridge. Niwa et al. [9] conducted an experimental study on the shearing behavior of the articulating gap between a new bridge and a widened hollow slab bridge, but they did not discuss the difference between articulated connection and rigid connection. $\mathrm{Wu}$ [10] carried out an experimental investigation on the lateral distribution of beam settlement in the widened bridge of a wide hollow slab. However, Wu did not explain the role of reinforcement transverse beam. In a word, these studies did not consider the impacts of widening on the bearing capacity of bridges. They all assumed the bearing capacity of bridges was constant throughout the reconstruction.

Studies on the widening of highway bridges in China are mainly based on engineering practices, especially on the widening of a specific bridge [11]. Reinforced concrete bridges with a simply supported T-shaped girder and plate girders are generally reinforced by using more girders. These new girders ( $\mathrm{T}$-shaped girder or plate girder) may have either the same section size with or larger section size than the original superstructure. Such reinforcement is the prototype of the widening of highway bridges. In early studies, researchers emphasized on the transverse load distribution of beams but did not analyze the influence of beam connection mode on the overall performance of the widened structure, but the longitudinal cracking at joint positions occurs frequently. $\mathrm{Li}$ [12] explored the widening of orthotropic steel cantilever slab on concrete box girder. However, this widening technique requires the original girders to meet the desired bearing capacity. Although Wang [13] proposed the concept of widening and reinforcement with longitudinal and transverse beams, he did not discuss the variation law of the LDF of girders.

LDF is typically calculated by lever principle method, eccentric compression method, transverse articulated slab (girder) method, transverse rigid-joint girder method, and quasi-orthotropic plate method [14]. Guo [15] proposed the proportional expression, which takes deflection, bending moment, shearing force, and the load of side and middle beams into consideration, and compiled a calculation program for LDF. However, new transverse beams were excluded from the program. Zhang [16] deduced a transverse load expression by regarding structural rigidity increase of side beams to middle beams as a piece of virtual girder, and claimed that the transverse load distribution of old girders could not be further improved if the rigidity of large side beams increases to a certain value. Nevertheless, Zhang did not compare the redistribution of transverse loads between side and middle beams. Bao [17] performed a scale-model test on the reinforcement of exiting bridges with large side beams, and proposed a formula for calculating LDF that involves rigidity correction. However, this formula neither satisfied the accuracy nor considered the effects of new transverse beams.

Few researchers combined widening and reinforcement, or considered the variation law of the LDF of beams. In the current study, changes of the LDF under different positions, quantities, and rigidities of beams and connection mode were analyzed.

The rest of the study is organized as follows: a widening and reinforcement design method with longitudinal and transverse beams is proposed, and a method for calculating the LDF is introduced in section 3. In section 4, the reliability and feasibility of the proposed design method of a simply supported bridge are verified. A comparative analysis on LDF before and after the reconstruction is carried out. In section 5 , the conclusions are presented.

\section{Methodology}

3.1 Widening and reinforcement design with longitudinal and transverse beams

In this section, a new widening and reinforcement method for existing bridges with longitudinal and transverse beams was proposed. The core idea lied in the side girders (widened parts at two sides) and widened beams (reinforced existing beams), as shown in Fig. 1. Beam connections were reinforced to improve the integrity of the bridge and decrease loads on single beam. Consequently, the bearing capacity of the entire bridge was improved by widening and reinforcement design.

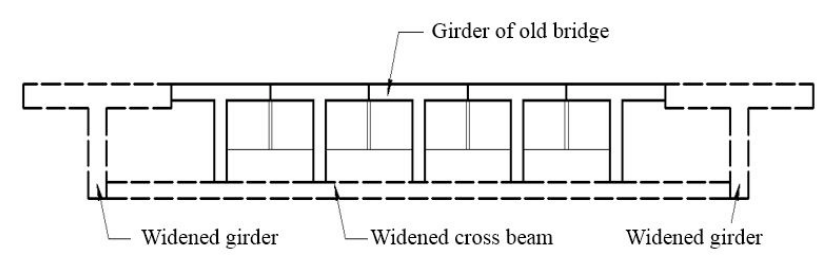

(a) Sectional view

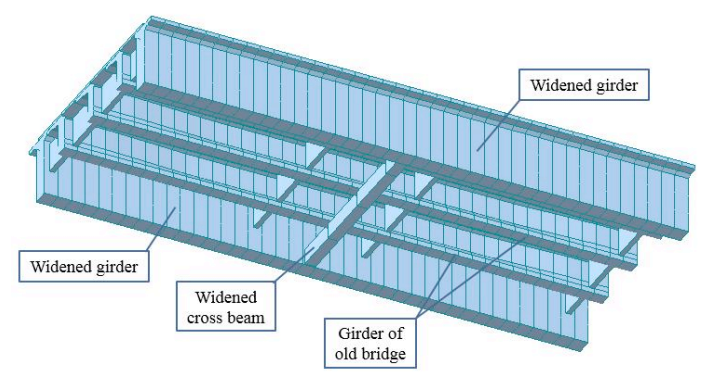

(b) $3 \mathrm{D}$ view

Fig. 1. Widening and reinforcement design

\subsection{Calculation of LDF}

The old bridge was widened and reinforced by longitudinal and transverse beams. Two hypotheses were proposed: (1) all girders were connected rigidly and the shear force and bending moment at nodes were transmitted each other. (2) if the bridge has a total of $\mathrm{n}$ girders $(1,2,3, \ldots, \mathrm{n})$ after the reconstruction, the connecting nodes are calculated as $n-1$. The mechanic mode of the node $\mathrm{i}$ is shown in Fig. 2. $\mathrm{P}=1$ on beam $i$ and redundant forces at node $i-1, i$, and $i+1$ are the external force and redundant forces may influence the load distribution at node $\mathrm{i}$. 


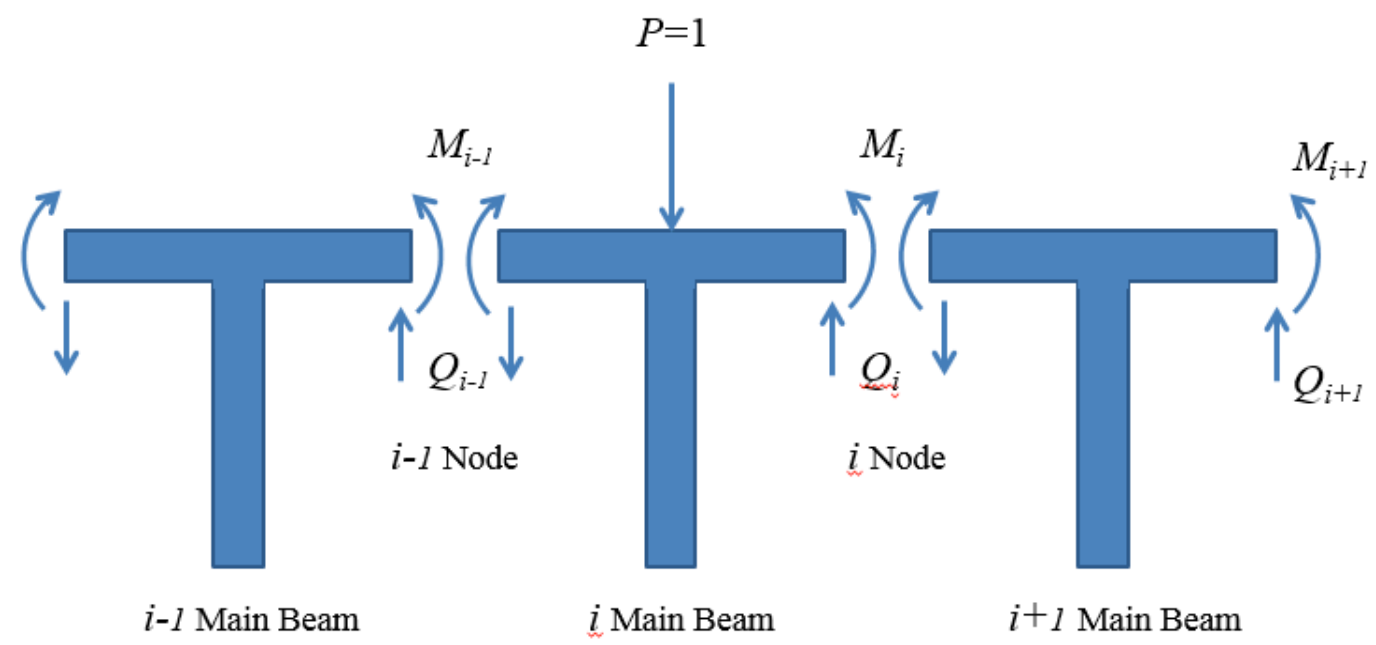

Fig. 2. Force analysis of node i

According to the deformation coordination conditions of node $i$, the relative deflection and corner at the left and right sides of node $i$ need to be equal. Then,

$$
\left[\delta_{i, i-1}\right]\left\{\mathrm{X}_{i-1}\right\}+\left[\delta_{i, i}\right]\left\{\mathrm{X}_{i}\right\}+\left[\delta_{i, i+1}\right]\left\{\mathrm{X}_{i+1}\right\}+\left\{\Delta_{i}\right\}=0
$$

where $i$ represents unit nodes $(i=2,3, \ldots, \mathrm{n}-2)$. When $i=1$, no $\left\{\mathrm{X}_{i-1}\right\}$ exists. When $i=n-1$, no $\left\{\mathrm{X}_{i+1}\right\}$ exists. $\left[\delta_{k}\right]=\left\{\begin{array}{l}\varphi_{i} \\ v_{i}\end{array}\right\}$ is the flexibility matrix, which is the displacement at node $\mathrm{i}$ caused by the unit redundant force at node k. $\left[X_{k}\right]=\left\{\begin{array}{l}M_{k} \\ Q_{k}\end{array}\right\}$ is the redundant force at node $k$ (bending moment and shearing force). $\left\{\Delta_{i}\right\}$ is the displacement of node $i$ caused by the unit load (rotation angle and deflection).

For the bridge with $i$ beams and $i-1$ nodes, the regular equation of the force method is

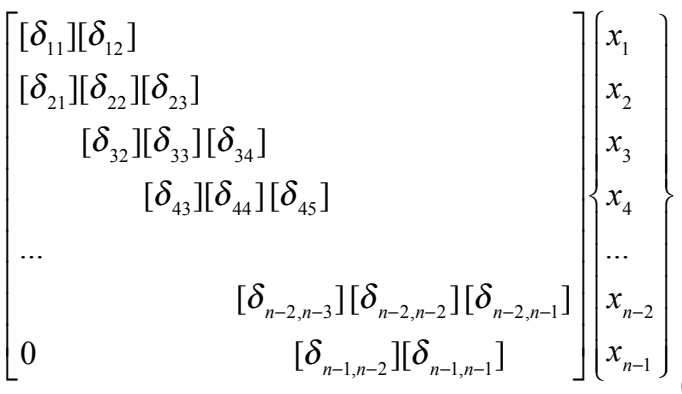

$$
\begin{aligned}
& +\left\{\begin{array}{l}
\Delta_{1} \\
\Delta_{2} \\
\Delta_{3} \\
\Delta_{4} \\
\cdots \\
\Delta_{n-2} \\
\Delta_{n-1}
\end{array}\right\}=0
\end{aligned}
$$

Equation (2) can be rewritten as:

$$
[\mathrm{A}]\{X\}+\{\Delta\}=0
$$

Where [A] is the total flexibility matrix, $\{X\}$ is the redundant force vector of the node which needs to be calculated, $\{\Delta\}$ is the node displacement, which is related to the load position. After solve Eq. (2) under different load positions, $\{X\}$ can be calculated.

\section{Result Analysis and discussion}

\subsection{Experimental settings}

The sectional view of a $30-\mathrm{m}$ span bridge with prestressed concrete T-shaped beams is shown in Fig. 3. It is composed of five T-shaped beams. The bridge width is $12.5 \mathrm{~m}(0.5 \mathrm{~m}$ (crash barrier) $+11.25 \mathrm{~m}$ (traffic lane) $+0.5 \mathrm{~m}$ (crash barrier)). The vehicle load and importance factor are originally designed to be load -over 20 and 1.0. The height and width of T-shaped cross section are 2 and $2.5 \mathrm{~m}$. These T-shaped beams are paved at an interval of $2.5 \mathrm{~m}$. The antibending moment of inertia is $0.501 \mathrm{~m} 4$, and the anti-torque moment of inertia is $0.0208 \mathrm{~m} 4$. The interval and height of the transverse diaphragm are 5 and $1.34 \mathrm{~m}$, respectively. The web of the beam is $0.2 \mathrm{~m}$.

The bridge was widened and reinforced by longitudinal and transverse beams. Two girders $(B \times H=290 \times 230 \mathrm{~cm})$ were added at the left and right sides, respectively. The depth of flange plate and web of the beam are both $30 \mathrm{~cm}$. The anti-bending and anti-torque moments of inertia of the reinforcement girder are 0.676 and $0.0455 \mathrm{~m} 4$, respectively. The size of the widened beam is designed as $B \times H \times L=$ $30 \times 30 \times 1,510 \mathrm{~cm}$.

\subsection{Effects of the position and quantity of widened beams}

After widening reinforce existing bridge with longitudinal and transverse beams, the LDF of the midspan section under four cases were calculated. For Case 1, no girder and beam was added on the bridge. For Case 2, one transverse beam was added at midspan. For Case 3, one cross beam was applied at 1/3-span. For Case 4, one cross section was paved at midspan and $1 / 4$-span. The weight of the widened beam was equivalent to the height of the transverse diaphragm, and the rigidity of girder was calculated by the rigidity of the transverse diaphragm. Calculated results are shown in Fig. 4 


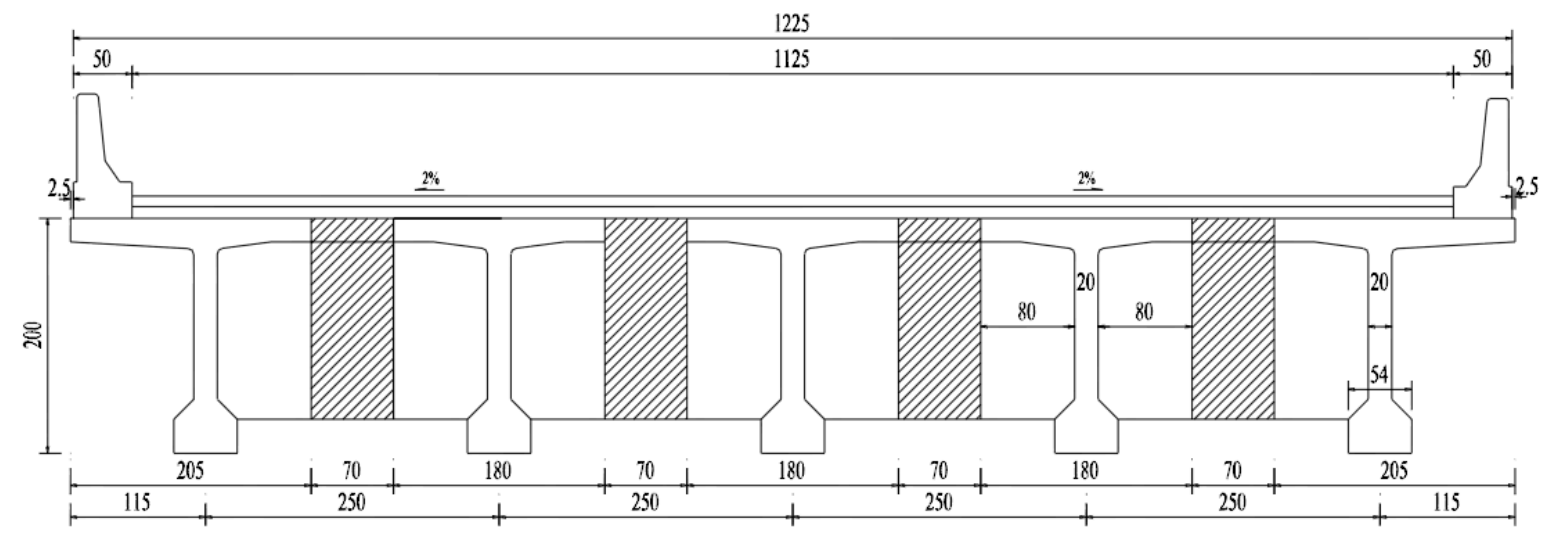

Fig. 3. Midspan cross section drawing (unit: $\mathrm{cm}$ )

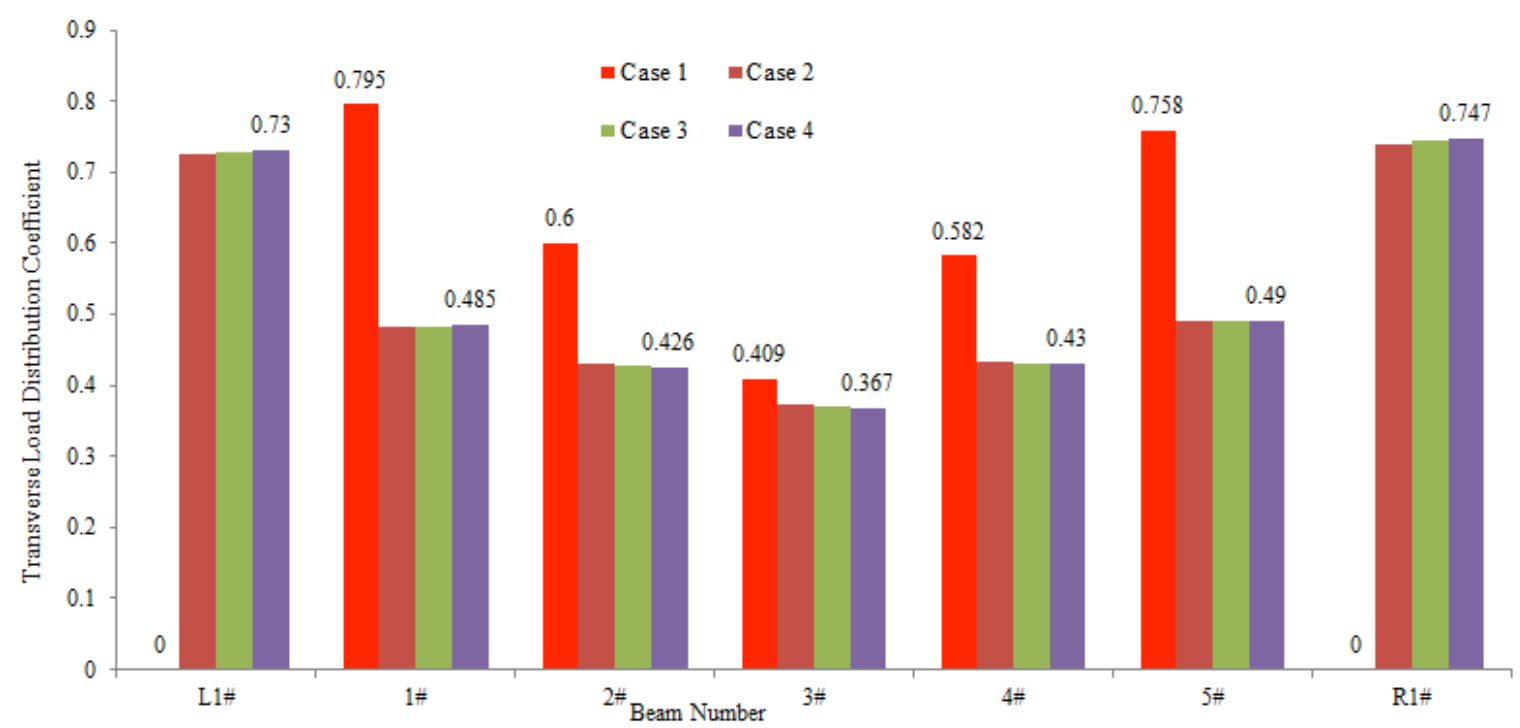

Fig. 4. LDF in the four different cases

Note: Numbers only represent the LDF in the four cases.

In Fig. 4, the LDF of beams after the widening drops sharply compared to those before. The LDF of side beams (Beams \#1 and \#5) decreases by $63.92 \%$ and $54.69 \%$, respectively. The maximum loads and the maximum internal forces of beams decrease relatively. Moreover, the LDF of beams have no evident changes with the different quantities and positions.

\subsection{Effects of widened beam rigidity/original girder rigidity}

The effects of the rigidity of beams on the LDF were analyzed by applying one transverse beam at midspan. The rigidity of beams was expressed by beam size. Three working conditions (beam size) were set in this study. For Cases 5, 6, and 7, the beam sizes are $30 \times 30 \times 1,510 \mathrm{~cm}$, $50 \times 30 \times 1,510 \mathrm{~cm}$, and $50 \times 50 \times 1,510 \mathrm{~cm}$, respectively. The results are listed in Table 1.

Table 1. Parameters of the four real-world networks

\begin{tabular}{c|c|c|c|c|c|c|c} 
Bases & L1 & \#1 & \#2 & \#3 & \#4 & R1 \\
\hline Case 5 & 0.725 & 0.483 & 0.430 & 0.373 & 0.433 & 0.491 \\
Case 6 & 0.727 & 0.483 & 0.428 & 0.371 & 0.432 & 0.739 \\
Case 7 & 0.730 & 0.483 & 0.427 & 0.367 & 0.430 & 0.490 \\
\hline
\end{tabular}

Table 1 shows that the LDF of beams is insensitive to beam size, and the rigidity ratio of the beams to girders of the bridge. According to Fig. 4, the proposed widening and reinforcement design method with longitudinal and transverse beams can be used without limiting the quantity, position or stiffness of the transverse beams.
4.4 Effect of connection mode between widened beams and old girders

The LDF of beams under articulated connection and rigid connection between widened beams and old girders were calculated (Fig. 5). 


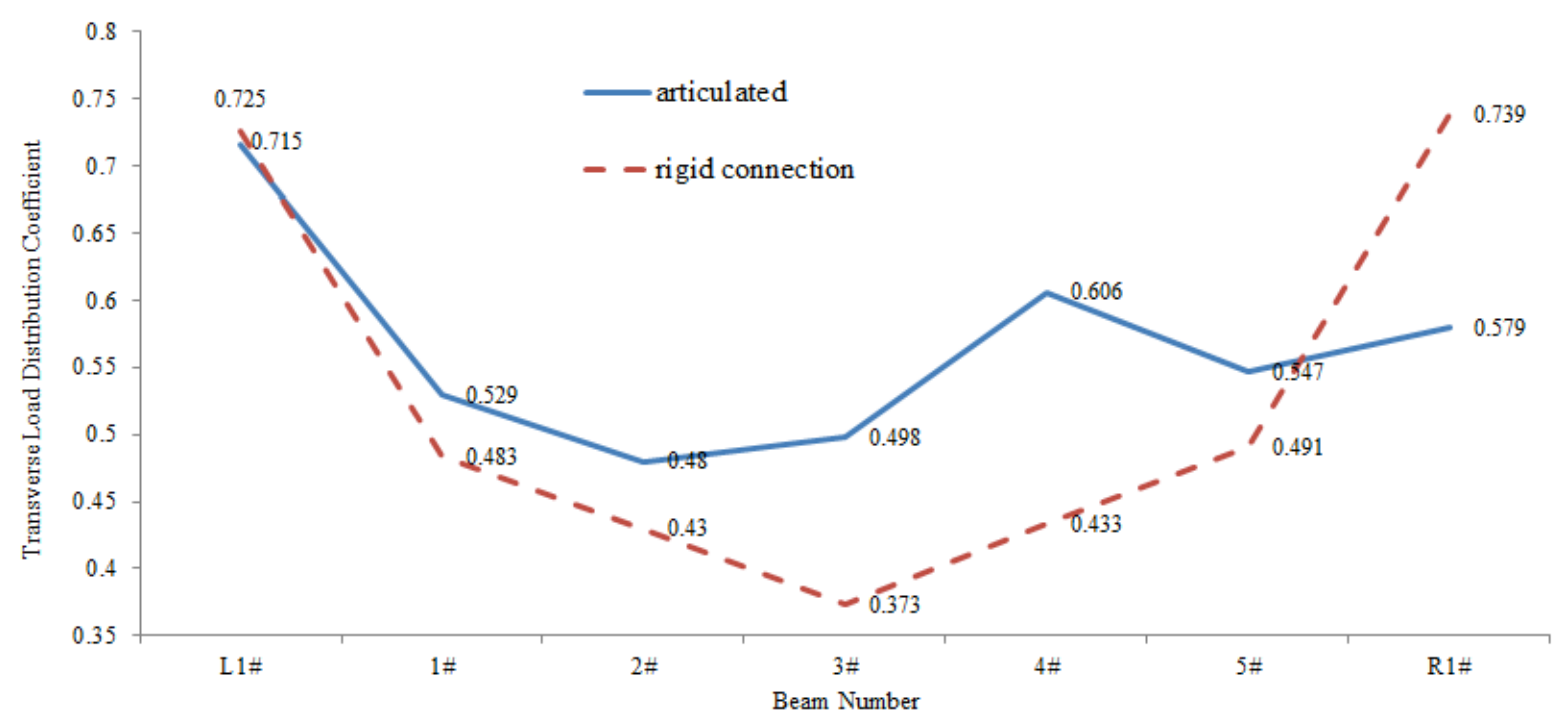

Fig. 5. LDF of beams with rigid/articulated connections

Figure 5 shows that with the articulated connection, the LDF of Beams \#1 to \#5 are 9.52\%, $11.63 \%, 33.51 \%$, $39.95 \%$, and $11.41 \%$ higher than those with the rigid connection. However, the LDF of L1 and R1 beams with articulated connection are $1.4 \%$ and $27.63 \%$ lower than those under rigid connection, respectively. In addition, the LDF of beams fluctuates more sharply with rigid connection.
Thus, articulated connection is recommended for the widening and reinforcement of bridges.

\subsection{Effects of connection mode between widened girders} and widened beams

The LDF of beams with articulated connection and rigid connection between widened girders and widened beams are shown in Fig. 6.

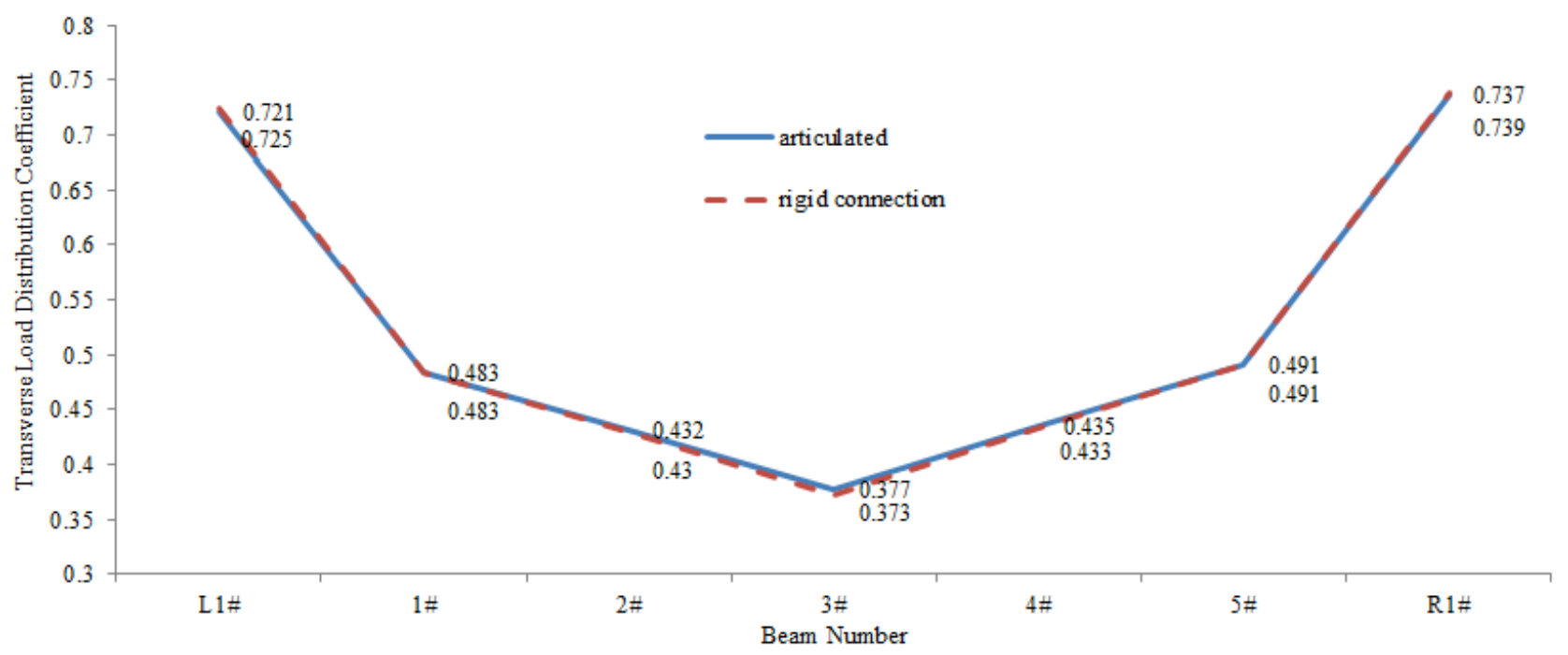

Fig. 6. LDF of beams with the different connections

Note: The solid line represents the LDF with the articulated connection, and the dotted line represents the LDF with rigid connection.

Figure 6 shows a small difference in the LDF. This result reveals that the connection mode of widened girders and widened beams will not significantly influence the overall performance of the widened bridge. In both connection modes, the LDF of side beams are negatively correlated with those of middle beams, LDF value distribution of the adjacent transverse beams are as shown in "V" shape.

\subsection{LDF at fulcrums}

The LDF of beams at fulcrums before and after the reconstruction were calculated by lever principle method (Fig. 7). 


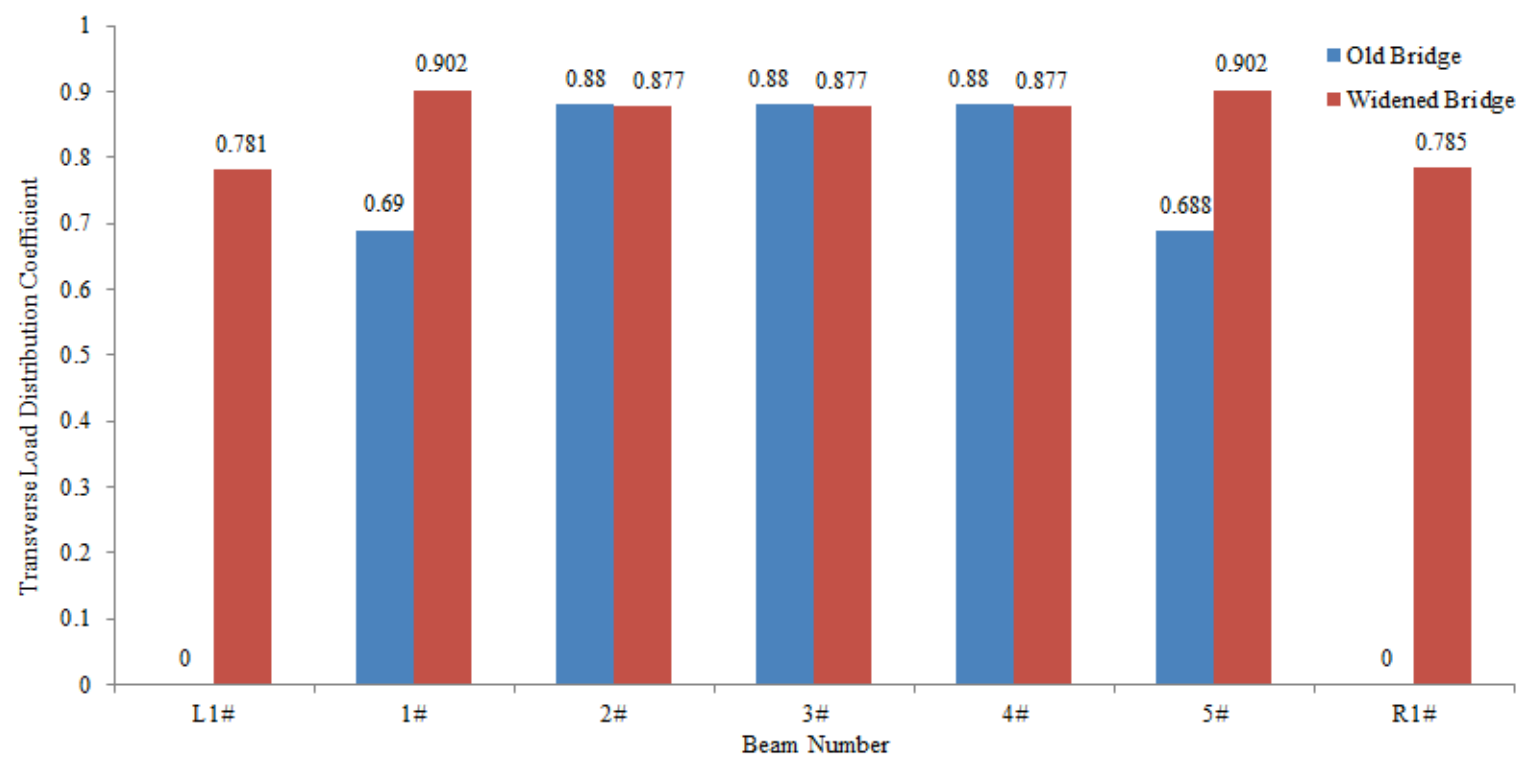

Fig. 7. LDF of beams at fulcrums before and after the reconstruction

In Fig. 7, the LDF of side beams (Beams \#1 and \#5) at fulcrums after the reconstruction are respectively $30.72 \%$ and $31.10 \%$ higher than those before, while the LDF of middle beams remain approximately the same. This result implies that the fulcrums of old girders require strengthening during widening and reinforcement.

\section{Conclusions}

To study the changing regularity of LDF before and after widening and reinforcement of existing bridges, the LDF of beams with different positions, quantities, and connection modes were discussed based on a new widening and reinforcement method for existing bridges. The main conclusions are as follows:

(1) The widening and reinforcement method with longitudinal and transverse beams can significantly reduce the LDF of old girders. In other words, the bearing load of a single beam can be reduced and the bearing capacity of the entire bridge can be increased with this method. However, some reinforcement measures should be performed because the LDF at fulcrum for side beams increase by $30 \%$.

(2) The LDF for widened girders are significantly lower than those of old girders. For side beams, it decreases by $63.92 \%$ at most. Nevertheless, LDF is not influenced sharply by beam quantity, position, and rigidity.

(3) The LDF of beams with rigid connection between a widened girder and old girders are smaller than those with articulated connection, and the articulated connection is recommended for widening old girders.
(4) Articulated connection and rigid connection are used for main beams and widened girders, respectively. The LDF before and after widening have no evident difference, and the LDF value distribution of the adjacent transverse beams are as shown in "V" shape.

In this study, the LDF of transverse beams of existed widened bridge was studied theoretically and practically. The proposed method presented in the paper can be used to improve the uniformity of load distribution and thereby increase the bearing capacity of the bridge. The conclusions can be referred for the development of future bridge reinforcement designs. However, beams were assumed to be bonded through rigid connection in the study, which is inconsistent with actual conditions. In practical engineering, beam damages may cause cracking and complete failure of the beam connection. Therefore, future theoretical studies should explore different actual connection modes of bridges or perform a field test.

\section{Acknowledgements}

This work was supported by the Scientific Research Project of Hunan Provincial Education Department (15C0125), the Science and Technology Program of Zhejiang Transportation Department (2017016), and the Special Projects Supported by Scientific Research Institutes of Zhejiang Science Technology Department(2017F30049).

This is an Open Access article distributed under the terms of the Creative Commons Attribution Licence

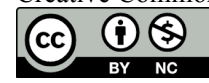

\section{References}

1. LIU Neng-wen, YANG Yong, "Analysis and optimization design method of diseases of hinged plate bridge". Journal of Highway and Transportation Research and Development, 33(2), 2016,pp.73-81.

2. SHAO Xu-dong, "Bridge Engineering (4th Edition)". Beijing: China Communications Press,2016,pp.113-114.

3. CHEN Ai-rong, YANG Yan-kai, MA Ru-jin,'Risk-based design method of disaster-resistance performance for bridge". Journal of Tongji University(Natural Science),44(7) ,2016,pp.991-995.
4. HUANG Li-pu, TAN Hai-liang, CAO Su-gong, JIANG Huan, LI Cong, "Study on lateral distribution coefficient of prefabricated simply supported T beam bridge".Journal of Changsha University,(5), 2011,pp.12-14.

5. WANG Min-qiang, XUE Fei, ZHANG Huang, XU Hong-chao, "Method of calculation of transverse load distribution influence line for an articulated slab girder bridge". Engineering Journal of Wuhan University, 37(4),2004,pp.68-72. 
L.P.Huang, S.G.Cao, C.L.Wei, Z.G.Chang, X.C.Zhang and Y.Z.Huang/

Journal of Engineering Science and Technology Review 10 (3) (2017) 90-96

6. WANG Xin-wen,'Domestic and overseas bridge dilated measures and technical analysis".The World of Building Materials,30(5), 2009,pp.105-108.

7. CHEN Yong-zhi,'Design of widening and strengthening of reinforced concrete T beam". Journal of Highway and Transportation Research and Development, (1),2013,pp.26-28.

8. Chai Y H, Hung H J.,"Waiting period for closure pours in bridge widening or staged construction". Journal of Bridge Engineering, 21(5), 2016,pp.04-16.

9. Niwa J, Fakhruddin, Matsumoto K, et al.,'Experimental study on shear behavior of the interface between old and new deck slabs". Engineering Structures, 126, 2016, pp.278-291.

10. WU Wen-Qing,S Yang,LZ Zhang," Study of distribution pattern of settlement deformation of main beams of a widened new slab beam bridge". Bridge Construction, 44(4) ,2014,pp.75-79.

11. ZONG Zhou-hong, XIA Zhang-hua, CHEN Yi-yan, ZHAO Xuanxian,"State-of-the-art and engineering example analysis of longitudinal connection joints between the new bridges and existing old bridges during bridge widening". Journal of Fuzhou University(Natural Science Edition), 37(2), 2009,pp.248-260.
12. LI Ze-tao, WANG Qian,"Existing beam bridge widening methods and ties application". Northern Communications, (2), 2015, pp.9-14.

13. WANG Guang-hui, WEI Cheng-long, ZHU Zhou-zhou. "Paremetric analysis of widening stringers and floor beams to strengthen existing T beam bridge". World Bridges, (5), 2015, pp.8590.

14. LI Bo, WU Jian, WANG Yong-lan,'Experimental study on transverse distribution coefficient of prefabricated $\mathrm{T}$ beam bridge under service" . Journal of China \& Foreign Highway, 35(5), 2015,pp.167-170.

15. GUO Yong-chen, YE Jian-shu,'Research on the method by adding large reforming the old bridge girder".East China Highway, (1), 1986,pp.40-48.

16. ZHANG Yuan-hai, LI Qiao,'Fictitious longitudinal beam method for practical spatial analysis of bridge structures with large side beams". Engineering Mechanics, 25(7), 2008,pp.185-189.

17. BAO Long-sheng, YU Ling, ZHOU Xiao- dan, GU Wei-an, YU Jian,"Test study of reinforced bridge models with border beams". Northeastern Highway, 26(2), 2003,pp.105-108. 